\title{
Patient Preferences: Results of a German Adaptive Choice-Based Conjoint Analysis (Market Research Study Sponsored by Eli Lilly and Company) in Patients on Palliative Treatment for Advanced Breast Cancer
}

\author{
Mattea Reinisch ${ }^{a} \quad$ Norbert Marschner $^{b}$ Thorsten Otto ${ }^{c} \quad$ Agnieszka Korfel $^{c}$ \\ Clemens Stoffregen $^{c}$ Achim Wöckel ${ }^{d}$ \\ ${ }^{a}$ Interdisziplinäres Brustzentrum/Senologie, Kliniken Essen-Mitte, Essen, Germany; ${ }^{b}$ Praxis für Interdisziplinäre \\ Onkologie und Hämatologie, Freiburg, Germany; ' Lilly Deutschland GmbH, Bad Homburg, Germany; ${ }^{d}$ Klinik für \\ Geburtshilfe und Gynäkologie, Universitätsklinik der Julius-Maximilians-Universität, Würzburg, Germany
}

Keywords

Advanced breast cancer - Patient preferences - Treatment · Survival $\cdot$ Conjoint analysis

\begin{abstract}
Introduction: Integration of patient preferences into shared decision making improves disease-related outcomes, but such data from patients with advanced breast cancer ( $\mathrm{aBC}$ ) are limited. The objective of this study was to demonstrate the relative importance of overall survival (OS) and progression-free survival (PFS) in relation to quality of life (QoL) and therapy-associated side effects from the perspective of patients with aBC. Methods: Postmenopausal patients with hormone receptor-positive, human epidermal growth factor receptor 2-negative $\mathrm{aBC}$ receiving first- or second-line treatment were recruited throughout Germany. Patient-relevant attributes for $\mathrm{aBC}$ therapy assessment were collected using a stepwise multimodal approach. A conjoint matrix was developed, resulting in 2 attributes for therapy goals (OS and PFS), 4 for QoL, and 6 for side effects. An online quantitative survey was then performed using adaptive choice-based conjoint $(\mathrm{ACBC}$ ) methodology. Results: The quantitative survey included 104 patients: 67 (64.4\%) receiving first-line treatment and 37 (35.6\%) receiving second-line treatment. The QoL attribute "physical agility and mobility" received the
\end{abstract}

karger@karger.com www.karger.com/brc

Karger $\%$ BOPEN ACCESS
(C) 2021 The Author(s)

Published by S. Karger AG, Basel

This is an Open Access article licensed under the Creative Common Attribution-NonCommercial-4.0 International License (CC BY-NC) (http://www.karger.com/Services/OpenAccessLicense), applicable to the online version of the article only. Usage and distribution for commercial purposes requires written permission. highest utility score (19.4 of $100 \%)$, reflecting the greatest importance to patients, followed by treatment goals (OS [15.2\%] and PFS [14.4\%]). Therapy-related side effects were less important, with nausea/vomiting being the most important (9.3\%), followed by infection (6.4\%) and hair loss (5.0\%). The McFadden pseudo $R^{2}(0.805)$, the root likelihood (0.864), and the $X^{2}$ test $(2,809.041 ; p<0.0001)$ indicated a very good fit of the statistical model. Conclusion: Using ACBC analysis, it appears that QoL, OS, and PFS are most important to postmenopausal patients with $\mathrm{aBC}$ in relation to cancer treatment. Side effects seem to be less important if OS or PFS are prolonged and the QoL is maintained. Thus, QoL, OS, and PFS should be considered equally when making treatment decisions in $\mathrm{aBC}$.

(C) 2021 The Author(s)

Published by S. Karger AG, Basel

\section{Introduction}

Endocrine therapies (ET) are the standard treatment for patients with advanced hormone receptor (HR)-positive and human epidermal growth factor receptor 2 (HER2)-negative breast cancer. However, ET can be or become ineffective in HR+/HER2- breast cancer due to primary or acquired endocrine resistance. Recently, several strategies and products have been developed to over- 
come the problem of resistance and improve therapeutic results; e.g., combining endocrine agents and drugs interfering with other metabolic and cell cycle pathways [reviewed in 1-3]. In particular, cyclin-dependent kinase 4/6 (CDK4/6) inhibitors that block the tumor cell at a key site and thus prevent subsequent cell division have recently been introduced. Since these agents act downstream of hormone-dependent stimulation, it is rational to combine them with an ET [1-3].

Collecting patient preference data has become increasingly important in recent years $[4,5]$. Patient-centered care enabling patients to contribute to treatment decisions and self-management improves therapy adherence and long-term disease control, physician-patient relationships, disease-related outcomes, and patient quality of life (QoL) [6]. The results of studies investigating patient preferences could influence the decision making of both physicians and regulatory authorities $[4,7]$.

Patient preference data from quantitative studies focusing on advanced breast cancer $(\mathrm{aBC})$ are limited $[8,9]$. Specifically, no patient preference data in women with HR+/HER2- locally advanced (stage IIIb) or metastatic breast cancer (stage IV) have been collected in Germany to date. Therefore, the present study served to generate such data. The objective was to demonstrate the relative importance of overall survival (OS) and progression-free survival (PFS) in relation to QoL and therapy side effects from the perspective of patients with aBC.

Conjoint measurement represents the gold standard in patient preference research. In contrast to direct and isolated evaluation of individual attributes, in the conjoint approach, various attributes of a subject are CONsidered JOINTly before preference evaluations are made. Choice-based conjoint (CBC) analysis has been used in a number of patient preference studies in a variety of settings, including breast cancer, non-small cell lung cancer, osteoarthritis, and diabetes $[8,10-15]$. The specific variant applied here was adaptive CBC (ACBC) measurement, which again has repeatedly been used successfully for patient preference research [13-15] and was considered most appropriate for present purposes since, in contrast to $\mathrm{CBC}$ analysis, it ensures best personal relevance to each respondent [14].

\section{Materials and Methods}

A multistep empirical study was conducted in Germany; the qualitative phase was in July 2017 and the quantitative phase was between November 2017 and February 2018.

\section{Patient Sample}

Participating respondents were required to meet the following criteria: female, postmenopausal, aged $\geq 50$ years, locally advanced or metastatic HR+/HER2- breast cancer (de novo or relapsed), primary or secondary endocrine resistance, and ongoing systemic treatment (first or second line). Patients were recruited via treating physicians (office- or hospital-based oncologists or gynecologists specialized in oncology who were unaware of which patients participated), patient organizations, oncology forums, social media, and relevant events.

Prior to interview, patients were comprehensively informed about the voluntary, confidential, and anonymous nature of the research, and about data privacy and so on, according to the European Pharmaceutical Marketing Research Association (ESOMAR)/European Society for Opinion and Market Research (EPhMRA) code of conduct. Written consent to participate was collected from each respondent.

\section{Study Design}

This study was based on the checklist of the International Society for Pharmacoeconomics and Outcomes Research (ISPOR) Good Research Practices for Conjoint Analysis Task Force [16], other methodological publications [5, 14], and the IQWiG study on preference measurement in periodontal disease [17]. Reporting was based on ISPOR and International Committee of Medical Journal Editors (ICMJE) recommendations $[16,18]$.

We used a standard stepwise multimodal approach consisting of 3 phases: (1a) desk research, (1b) qualitative in-depth interviews, and (2) quantitative online survey using the ACBC method$\operatorname{ology}$ (Fig. 1).

\section{Desk Research}

The main objectives of the desk research were to obtain input on the topics to be investigated during the qualitative phase and the attributes that $\mathrm{aBC}$ patients considered important in forming their attitudes about cancer therapies. The search was conducted both off- and online (primarily using Google, PubMed, information from patient organizations, cancer institutes, etc.) and yielded a comprehensive catalog of treatment characteristics along with various options for expressing different levels of the attributes. These were used to develop the discussion guide for the qualitative phase.

\section{Qualitative Phase}

The qualitative phase consisted of 17 in-depth interviews (faceto-face or via telephone), lasting $60 \mathrm{~min}$ each, with $12 \mathrm{aBC}$ patients, 3 caregivers, and 2 physicians. The patient field was closed after 12 interviews, since this sample size provided sufficient information to develop the conjoint matrix for the quantitative phase; further patient interviews would have delivered only redundant information according to the principle of data saturation from grounded theory [19]. The interviews explored which attributes played a critical role in therapy assessment and decisions. They included questions about disease history, everyday living with aBC, therapy decisions, therapy goals, QoL, experiences, and dealing with side effects. The purpose of the interviews with physicians and caregivers was to complement and contrast patient responses from an external perspective. All interviews were audio-recorded, transcribed, and analyzed through qualitative content analysis following methodology for structured content analysis as proposed by Mayring [20].

\section{Quantitative Phase}

This phase was executed as an online survey, the core element of which was conjoint measurement. It also addressed patient demographics, patient and treatment history, side effects, and breast cancer information sources used. The survey took about $30 \mathrm{~min}$ to complete. Based on findings from the prior phases, a draft conjoint matrix (i.e., the attributes and levels used to describe different therapy options to participants) was developed, which was validated 


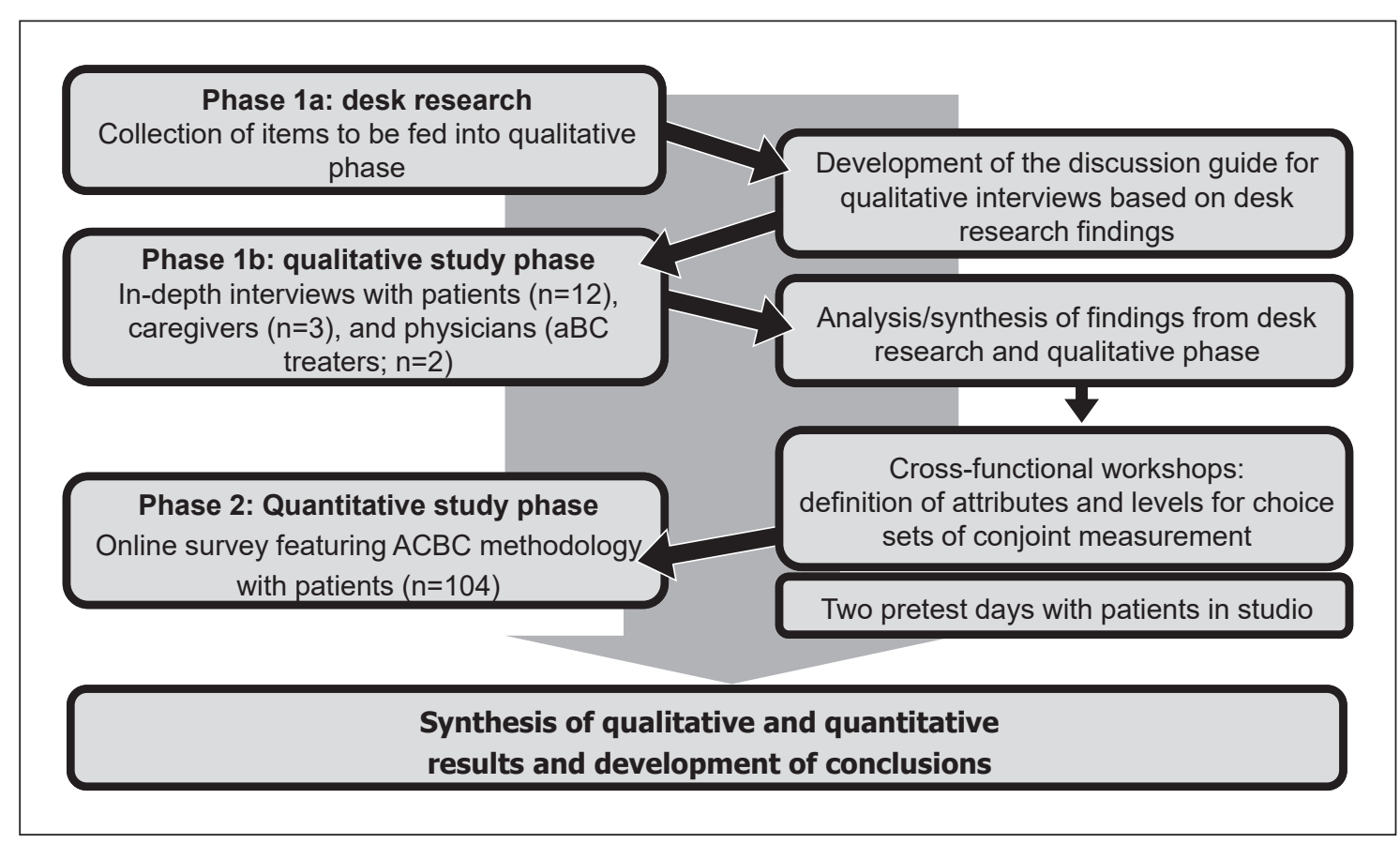

Fig. 1. Study design. aBC, advanced breast cancer (includes locally advanced and metastatic breast cancer); ACBC, adaptive choice-based conjoint.

and further refined in terms of wording and comprehensibility of questions/items by means of 2 pretests (observed answering of the questionnaire with subsequent discussion of comprehensibility and difficulty) with 4 (first pretest) and 5 (second pretest) aBC patients. Consequently, the final matrix (Fig. 2) consisted of 12 attributes: 2 therapy goals (OS and PFS, adjusted in the survey to patient language: "gained life time" and "gained time without disease progression"), 4 QoL components (emotional balance, participation in social life, physical agility and mobility, and flexibility throughout the course of the day/week), and 6 side effects (diarrhea, nausea/vomiting, hair loss, fatigue, dry mucosa, and risk of infection). The attributes were each split into 3 levels, reflecting different degrees of each feature (Fig. 2; online suppl. Tables 1-5; see www.karger.com/doi/10.1159/000513139 for all online suppl. material).

The final matrix (Fig. 2) served as the basis for ACBC measurement in this phase $[14,21,22]$, during which respondents completed iterative choice tasks (online suppl. Table 6).

\section{Sample Size}

A sample size of $\geq 125$ was determined according to the rule of Orme [23-25] (online suppl. Table 7); this was not entirely achieved due to methodological and practical requirements, such as strict inclusion/exclusion criteria (leading to a relatively high number of screen-outs during recruitment), limited accessibility to and availability of eligible participants, and timing and budget constraints.

The field work lasted from mid-November 2017 to the end of February 2018, at which point 104 questionnaires had been successfully completed. Tests were conducted to determine the numbers of patients receiving first- versus second-line treatment. The ratio of 67 first-line to 37 second-line patients proved sufficient to run the intended subgroup analysis with acceptable precision; thus, the survey was closed at this point.

Patient Preferences in Advanced Breast Cancer

\section{Statistical Analysis}

ACBC data were analyzed using a hierarchical Bayes (HB) approach. Individual choices were calculated via a logit-choice model using individual utility values. Group behavior was modelled using a multivariable normal distribution (group level). Model parameters for individual and group levels (total and first- vs. second-line patients) were calculated using a Gibbs sampling procedure. To compare individual values of the conjoint analysis, standardization was performed on an aggregated basis; raw $\mathrm{HB}$ values were averaged, and aggregate utility values within each feature were shifted so that the minimum value for all features was zero. All utility values were multiplied by a factor (sum of aggregated relative importance) such that the sum of the relative importance values equaled 100 [23].

To assess the goodness of fit of the statistical model, the following 3 criteria were calculated: the McFadden pseudo $R^{2}$, the root likelihood value, and the $\chi^{2}$ (likelihood ratio test statistic) value.

Statistical analysis was performed using Sawtooth ACBC/HB software, version 5.0 (Sawtooth Software; Orem, UT, USA).

\section{Results}

\section{Desk Research}

A total of 21 relevant studies were identified from the desk research (online suppl. Table 8 ), in which nausea, vomiting, diarrhea, fatigue, hair loss, and joint/muscle pain were the most frequently mentioned side effects, and OS and PFS were the most frequently mentioned treatment goals. 


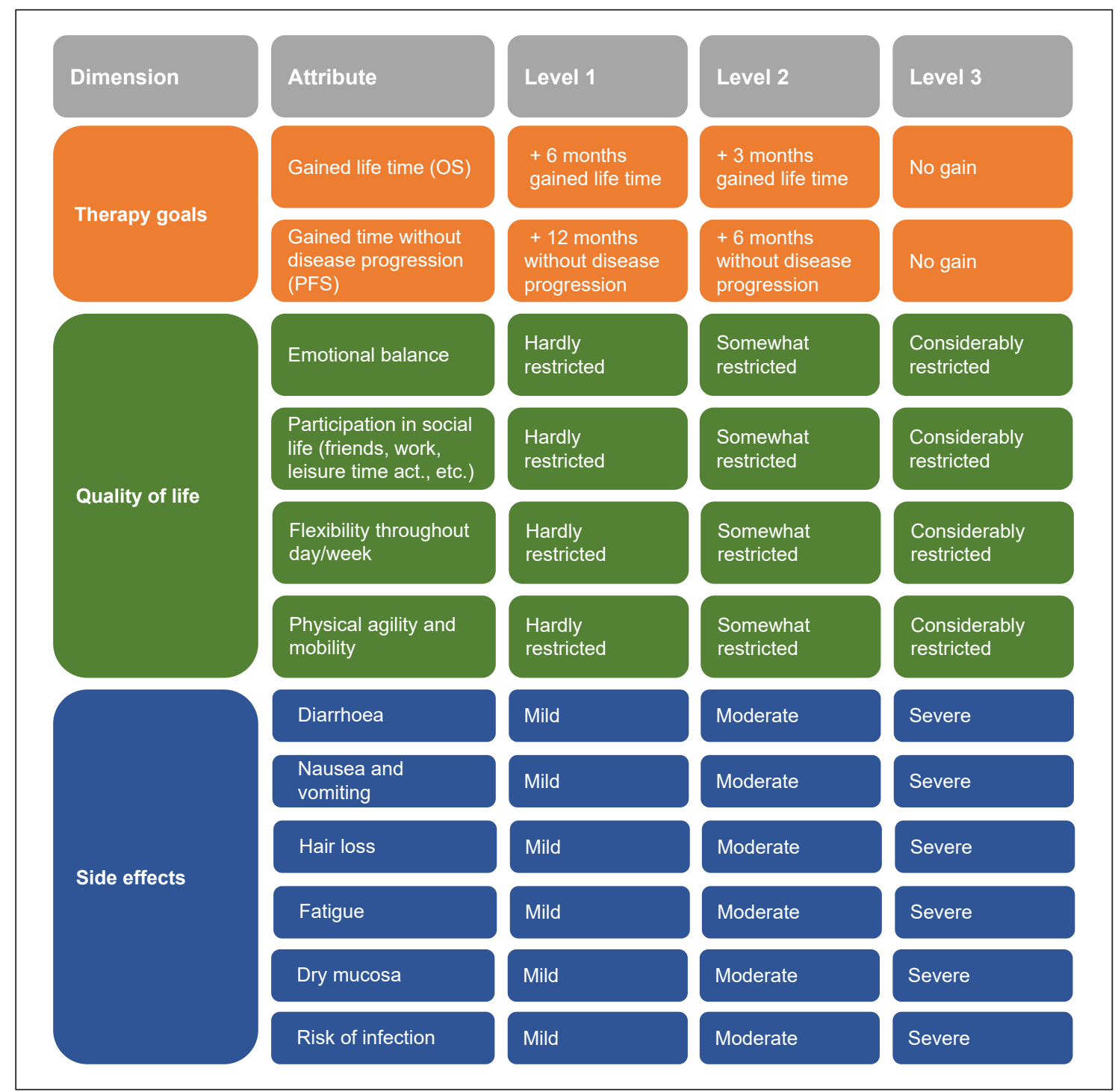

Fig. 2. Final conjoint matrix. act., activities; PFS, progression-free survival; OS, overall survival.

\section{Qualitative Phase}

In terms of therapy effectiveness, both PFS and OS were considered of great importance by patients, caregivers, and physicians; however, PFS appeared more tangible and relevant for patients in everyday life (something they can experience), whereas they tried not to think about OS. QoL emerged as a multidimensional concept consisting of several factors, such as the ability to lead a "normal" life, physical ability to do things as before, mobility, carefreeness (not continuously being reminded of the disease), having goals and being able to pursue them, and spending quality time with family and friends. Factors that impaired QoL were symptom burden, medical checkups, and side effects of anticancer therapy. The most frequently mentioned side effects were fatigue, hair loss, nausea/vomiting, sensory neuropathy, dry mucosa, bone/ joint pain, and infections. Patients used grades of varying degrees to describe the intensity of side effects. Side effects were considered particularly disturbing by patients if they were long lasting and affected everyday life, and if no effective management was available. Fatigue, diarrhea, nausea/vomiting, bone/joint pain, neurological side effects, and stomatitis were considered of major importance by both patients and physicians; the greatest difference in the weighting of side effects between these groups was for the significance of blood values (more important to physicians) and hair loss (more important to patients).

\section{Quantitative Phase}

Patient Demographics and Disease/Treatment History

A total of 104 patients with aBC participated in the online survey, 67 (64\%) receiving first-line therapy and 37 $(36 \%)$ receiving second-line therapy (Table 1). Seventy- 
Table 1. Patient demographics, and disease and treatment history (patients' self-assessment)

\begin{tabular}{|c|c|c|c|}
\hline \multirow[t]{2}{*}{ Disease and treatment history } & \multicolumn{3}{|c|}{ Proportion of patients, $\%$} \\
\hline & $\begin{array}{l}\text { total } \\
(n=104)\end{array}$ & $\begin{array}{l}\text { first-line } \\
\text { treatment } \\
(n=67)\end{array}$ & $\begin{array}{l}\text { second-line } \\
\text { treatment } \\
(n=37)\end{array}$ \\
\hline \multicolumn{4}{|l|}{ Age, years } \\
\hline $50-59$ & 52.9 & 53.7 & 51.4 \\
\hline $60-69$ & 32.7 & 31.3 & 35.1 \\
\hline $70+$ & 14.4 & 14.9 & 13.5 \\
\hline \multicolumn{4}{|l|}{ Working } \\
\hline Yes $^{\mathrm{a}}$ & 40.4 & 37.3 & 45.9 \\
\hline $\mathrm{No}^{\mathrm{b}}$ & 59.6 & 62.7 & 54.1 \\
\hline \multicolumn{4}{|l|}{ Relationship status } \\
\hline Married/long-term relationship & 67.3 & 68.7 & 64.9 \\
\hline Single & 29.8 & 29.9 & 29.7 \\
\hline Other & 2.9 & 1.5 & 5.4 \\
\hline \multicolumn{4}{|l|}{ Children } \\
\hline None & 31.7 & 26.9 & 40.5 \\
\hline $1-2$ & 59.6 & 62.7 & 54.1 \\
\hline 3 or more & 8.7 & 10.4 & 5.4 \\
\hline \multicolumn{4}{|l|}{ Classification } \\
\hline Relapse & 69.0 & 75.0 & 60.0 \\
\hline De novo disease & 31.0 & 25.0 & 40.0 \\
\hline \multicolumn{4}{|l|}{ Time of primary diagnosis } \\
\hline Up to 2 years ago & 12.5 & 16.4 & 5.4 \\
\hline $3-5$ years ago & 37.5 & 37.3 & 37.8 \\
\hline $6-10$ years ago & 29.8 & 31.3 & 27.0 \\
\hline$>10$ years ago & 20.2 & 14.9 & 29.7 \\
\hline \multicolumn{4}{|l|}{ Breast cancer stage at primary diagnosis } \\
\hline $\mathrm{IV}^{\mathrm{a}}$ & 26.9 & 19.4 & 40.5 \\
\hline IIIb & 18.3 & 16.4 & 21.6 \\
\hline I/II/III (relapsed patients only) ${ }^{c}$ & 54.8 & 64.2 & 37.8 \\
\hline \multicolumn{4}{|l|}{ Current breast cancer stage } \\
\hline IV & 88.5 & 86.6 & 91.9 \\
\hline IIIb & 11.5 & 13.4 & 8.1 \\
\hline \multicolumn{4}{|l|}{ Time of diagnosis of current stage } \\
\hline Up to 2 years ago ${ }^{c}$ & 45.2 & 59.7 & 18.9 \\
\hline $3-5$ years ago & 46.2 & 31.3 & 73.0 \\
\hline $6-10$ years ago & 7.7 & 7.5 & 8.1 \\
\hline$>10$ years ago & 1.0 & 1.5 & 0.0 \\
\hline \multicolumn{4}{|l|}{ Start of current anticancer treatment } \\
\hline $1-12$ months ( 1 year) ago & 43.0 & 33.0 & 62.0 \\
\hline $13-24$ months ( 2 years) ago & 27.0 & 27.0 & 27.0 \\
\hline $25-60$ months ( $3-5$ years) ago & 22.0 & 31.0 & 3.0 \\
\hline More than 60 months ( $>5$ years) ago & 8.0 & 9.0 & 5.0 \\
\hline \multicolumn{4}{|l|}{ Current anticancer drug treatment } \\
\hline Oral medication & 79.8 & 80.6 & 78.4 \\
\hline Injections & 28.8 & 23.9 & 37.8 \\
\hline Infusions & 15.4 & 14.9 & 16.2 \\
\hline \multicolumn{4}{|l|}{$\begin{array}{l}\text { Breast cancer treatments received } \\
\text { BEFORE diagnosis of aBC }\end{array}$} \\
\hline Breast surgery & 83.7 & 85.1 & 81.1 \\
\hline Lymph node dissection & 79.8 & 79.1 & 81.1 \\
\hline Radiation therapy & 75.0 & 74.6 & 75.7 \\
\hline Chemotherapy & 38.5 & 37.3 & 40.5 \\
\hline Hormone therapy & 15.4 & 17.9 & 10.8 \\
\hline Other & 2.9 & 3.0 & 2.7 \\
\hline
\end{tabular}

a Includes "employed", "self-employed" and "other". b Includes "unemployed”, "retired", "unfit for work" and "in education/vocational training". c The difference between patients receiving first- or second-line therapy was significant $(p<0.05)$. aBC, advanced breast cancer (includes locally advanced and metastatic breast cancer). 


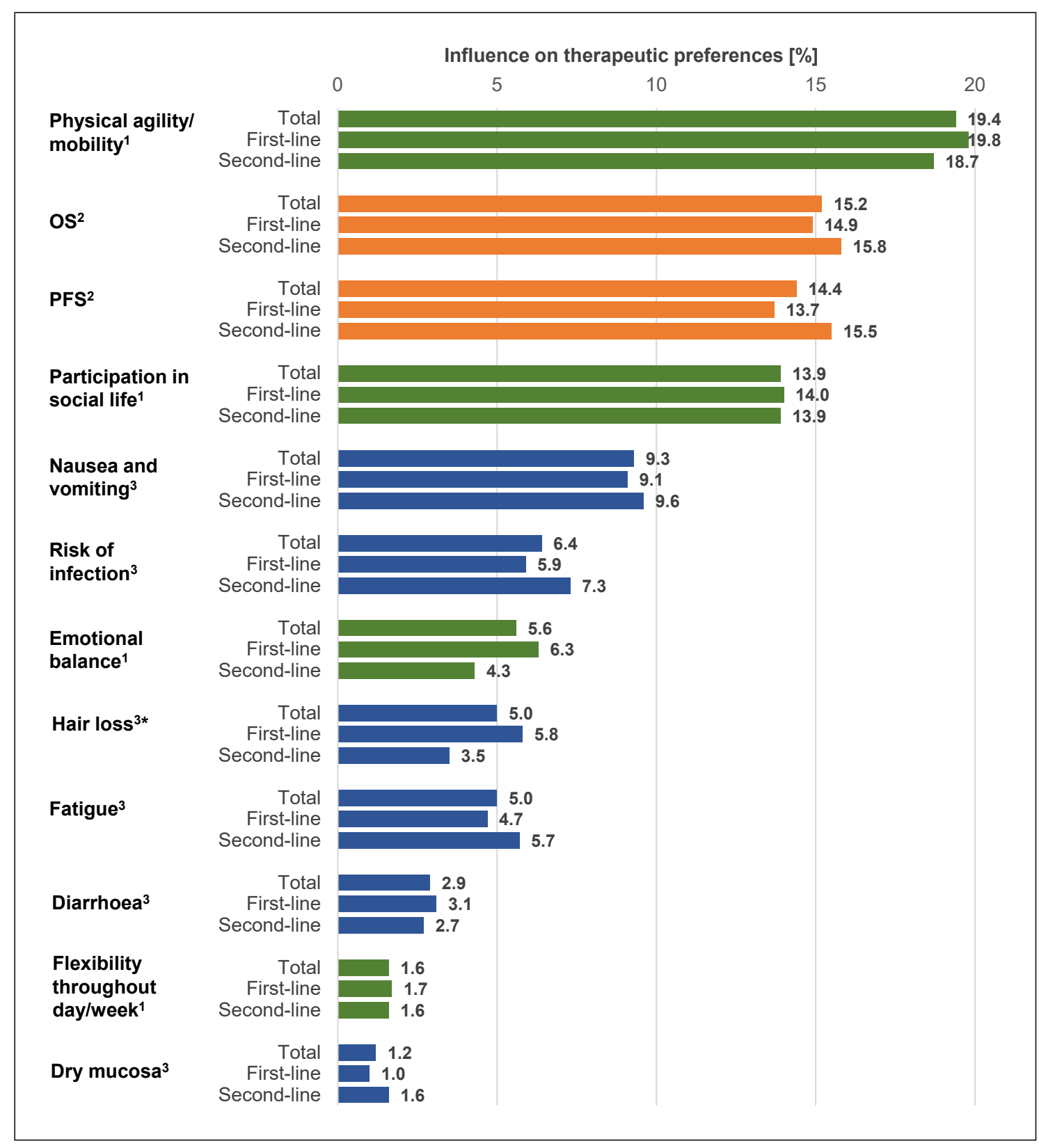

Fig. 3. Overview of the ACBC analysis results. Total: $n=104$ (first-line therapy, $n=67$; second-line therapy $n=$ 37). ${ }^{1}$ Dimension "quality of life." ${ }^{2}$ Dimension "therapy goals." ${ }^{3}$ Dimension "side effects." * Significant difference between first- and second-line therapy $(p<0.05)$. ACBC, adaptive choice-based conjoint; OS, overall survival; PFS, progression-free survival.

two patients (69\%) were in relapse and $32(31 \%)$ had de novo disease. The mean age was 61 years.

\section{Patient Preferences}

Figure 3 provides an overview of the final $\mathrm{ACBC}$ analysis results. "Physical agility and mobility", OS, PFS, and "social participation" affected the choice of therapy to the greatest extent, with a cumulative relative importance of over $60 \%$ (out of $100 \%$ ). Side effects were generally less important in treatment decisions. OS and PFS were slightly more important to patients receiving second-line treatment than to those receiving first-line treatment. There were no significant differences in individual QoL attributes between first- and second-line patients; overall, however, all QoL dimensions were marginally (but not significantly) more important to patients receiving firstline therapy. The most important side effect with regard to treatment decisions was "nausea and vomiting", followed by "risk of infection". Diarrhea and dry mucosa had little relevance to patients. There were no significant 
Fig. 4. Side effects that patients most frequently wished to avoid (total and by therapy line). Total: $n=104$ (first-line therapy, $n=67$; second-line therapy, $n=37$ ); patients chose 3 of 6 listed side effects that they would like to avoid if they had the choice between different treatment options.

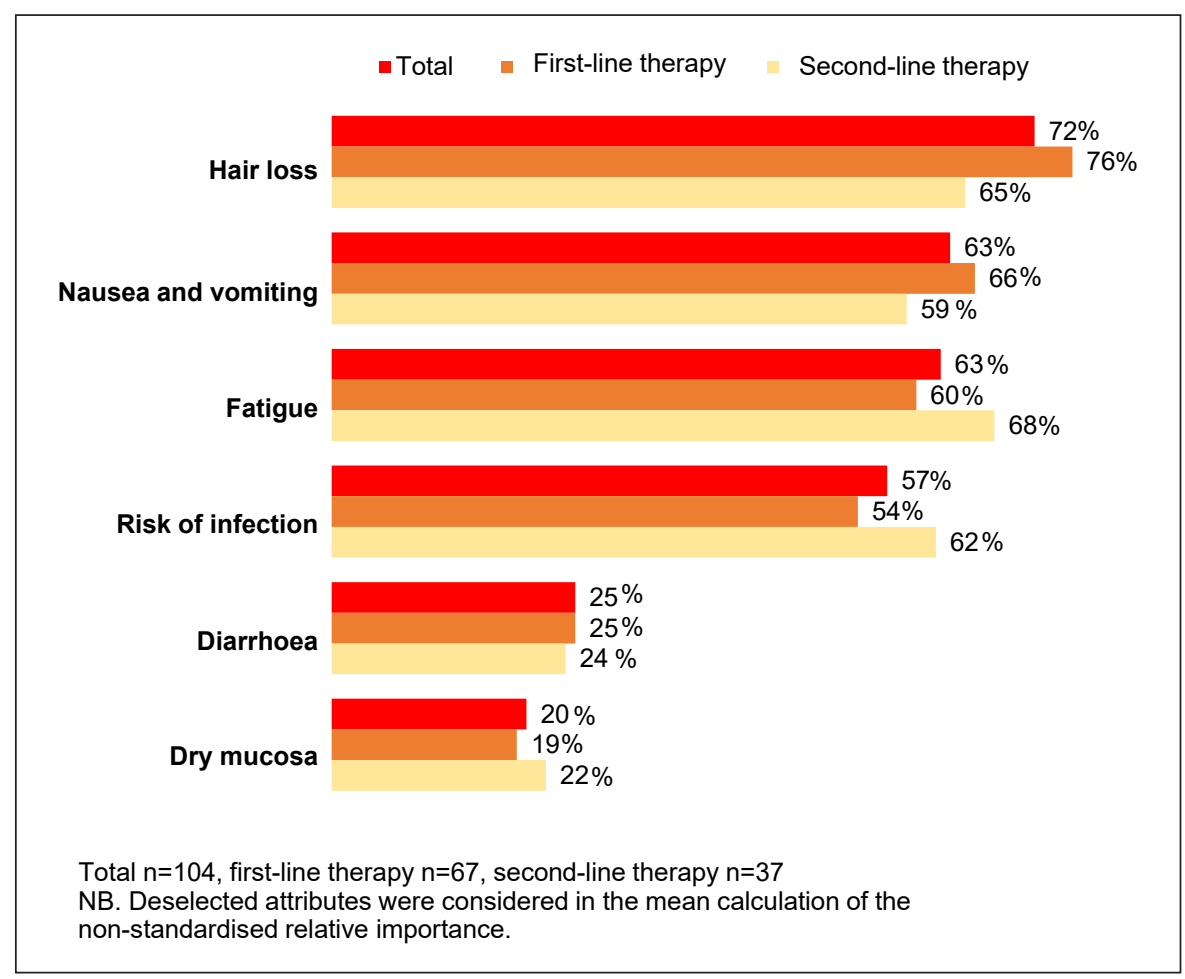

differences between first- and second-line patients in terms of side effects, with the exception of hair loss, which was significantly more important to first-line patients.

The side effects that patients most frequently wished to avoid were hair loss, nausea/vomiting, fatigue, and infection, and there were no major differences between first- and second-line patients (Fig. 4). A statistically significant association $(p<0.05)$ between having experienced the side effect and the desire to avoid it was found for nausea, vomiting, and dry mucosa (online suppl. Fig. 1).

The McFadden pseudo $R^{2}$ was 0.805 , the root likelihood value was 0.864 , and the $\chi^{2}$ test (likelihood ratio test statistic) result was $2,809.041$ ( $p<0.0001)$, indicating a very good fit of the statistical model. These results provide evidence that the attributes and dimensions were independent of each other, since they would not have been realized if major interactions existed within the conjoint matrix; consequently, no additional interaction tests were performed.

\section{Discussion}

This analysis showed that "physical agility and mobility", followed by OS, PFS, and "participation in social life", were the most important factors in therapy decisions for postmenopausal patients with HR+/HER2$\mathrm{aBC}$, retaining their importance independently of patients' previous treatment experiences. Conversely, gained lifetime was only desirable if achievable with maintained QoL. In accordance, patients were willing to accept side effects to an extent, provided that QoL was maintained and benefits in OS/PFS were achieved. Overall in this setting, avoiding side effects played a subordinate role; however, patients were particularly keen to avoid nausea and vomiting. Moderate limitations of QoL and moderate side effects were acceptable to patients, whereas severe limitations were not. Generally, no significant differences between patients receiving first-line therapy and those receiving second-line therapy were observed, indicating that previous experiences have little influence on treatment decisions.

Given the paucity of studies on patient preferences with regard to $\mathrm{aBC}$ therapy-related factors, our results cannot be easily compared with those of similar studies. In a survey of chemotherapy preferences among $121 \mathrm{pa}-$ tients (mean age 50 years) with stage I-IV BC who had received chemotherapy within the past 5 years, survival was the most important of the 12 attributes identified (including grade III/IV toxicities, efficacy, and administration regimen), with a high value placed on small incremental survival advantages associated with treatment despite the risk of serious toxicities [26]. The risk of neutropenia requiring hospitalization had the strongest impact on side effect preferences, followed by the risk of severe fatigue, nausea and vomiting, and diarrhea. Differences to our study are that the attributes were tailored to chemotherapy and QoL was not evaluated. Another study of 181 patients with aBC (mean age 52 years) found that 
OS was of highest importance to patients, followed by side effects (particularly alopecia, fatigue, and neutropenia) [8]. Patients were willing to accept substantial additional risks from side effects for gains in OS. Again, the survey design differed considerably from our survey, particularly with regard to surveying QoL, which only scored fifth highest in importance.

In contrast, Wouters et al. [27] showed that efficacy and side effects (those typically associated with ET) were similarly important to 241 patients with BC (mean age 57 years) who received ET. A recent patient preference study of 258 postmenopausal Japanese women with HR+ $\mathrm{BC}$ of different stages used a design specifically tailored to a combination of ET and the CDK4/6 inhibitor abemaciclib [9]. Attributes and their levels were selected based on the MONARCH 2 trial, which investigated abemaciclib plus fulvestrant compared to fulvestrant plus placebo [28]. Surveyed patients strongly preferred a treatment able to extend PFS despite the risk of grade 2 diarrhea. However, patients were more willing to sacrifice PFS to avoid more frequent occurrence of grade 3 diarrhea. Although the designs of these last 2 studies differed from that of our study and did not include QoL dimensions, they confirmed our finding that patients will accept trade-offs between the benefits and drawbacks of ET.

\section{Potential Limitations and Bias}

The attributes PFS and OS could not be deselected by patients, which may, theoretically, create bias by influencing the online survey results. However, sensitivity analysis produced almost identical utility values for OS and PFS. The high importance of PFS and OS was also in line with the qualitative results.

Finally, although a minority of patients were recruited via physicians, the majority responding to online posts in social media (patient organization websites, Facebook, etc.) or to flyers given out at patient congresses, participants required a letter of diagnosis from their treating physician unless they could answer the screening questions themselves. However, as participation was voluntary, we cannot rule out participant self-selection.

\section{Conclusion}

Using ACBC analysis, it appears that QoL, OS, and PFS are most and almost equally important to postmenopausal patients with $\mathrm{aBC}$ in relation to cancer treatment. Side effects seem to be less important if OS or PFS are prolonged and QoL is maintained. Thus, QoL, OS, and PFS should be considered equally for each individual patient when making treatment decisions with patients with aBC.

\section{Acknowledgement}

The authors thank all of the patients, caregivers, physicians, and investigators who participated in this study. They also thank Elke Weidling for consultancy, Exevia $\mathrm{GmbH}$ for managing the entire project, and IfaD $\mathrm{GmbH}$ for performing the multivariate analyses. The authors also acknowledge Dr. Julia Dittmann and Dr. Sue Chambers (Rx Communications, Mold, UK) for medical writing assistance with the preparation of this article, funded by Lilly Deutschland GmbH.

\section{Statement of Ethics}

As this was a market research study, ethical approval was not required. Informed consent was obtained from all of the participants.

\section{Conflict of Interest Statement}

Dr. Reinisch has received honoraria from AstraZeneca, Eli Lilly and Company, MSD, Novartis, Pfizer, and Roche for advisory boards and/or lectures, and travel/accommodation expenses from Celgene, Novartis, and Pfizer. Dr. Marschner has nothing to disclose. Prof. Wöckel has received honoraria from Amgen, AstraZeneca, Aurikamed, Celgene, Eisai, Eli Lilly and Company, MSD, Novartis, Pfizer, Roche, Sirtex, and Tesaro for advisory boards and/or lectures. Thorsten Otto, Agnieszka Korfel, and Clemens Stoffregen are employees of Eli Lilly and Company.

\section{Funding Sources}

This study was sponsored by Lilly Deutschland GmbH. The work was performed by Lilly Deutschland $\mathrm{GmbH}$ and Exevia $\mathrm{GmbH}$, funded by Lilly Deutschland $\mathrm{GmbH}$.

\section{Author Contributions}

M.R.: analysis and interpretation of data for this work and drafting and critical revision of this paper for important intellectual content. N.M.: interpretation of data for this work and critical revision of this paper for important intellectual content. T.O.: conception and design of this work, interpretation of data for this work, and critical revision of this work for important intellectual content. A.K.: interpretation of data for this work and drafting and critical revision of this paper for important intellectual content. C.S.: conception and design of this work, analysis and interpretation of data for this work, and critical revision of this work for important intellectual content. A.W.: analysis and interpretation of data for this work and critical revision of this paper for important intellectual content.

\section{References}

1 Ballinger TJ, Meier JB, Jansen VM. Current landscape of targeted therapies for hormonereceptor positive, HER2 negative metastatic breast cancer. Front Oncol. 2018 Aug;8:308.

2 Pernas S, Tolaney SM, Winer EP, Goel S. CDK4/6 inhibition in breast cancer: current practice and future directions. Ther Adv Med Oncol. 2018 Jul;10:1758835918786451. 
3 Reinert T, de Paula B, Shafaee MN, Souza PH Ellis MJ, Bines J. Endocrine therapy for ERpositive/HER2-negative metastatic breast cancer. Linchuang Zhongliuxue Zazhi. 2018 Jun;7(3):25.

4 van Til JA, Ijzerman MJ. Why should regulators consider using patient preferences in benefit-risk assessment? Pharmacoeconomics. 2014 Jan;32(1):1-4

5 Mühlbacher AC, Bethge S, Tockhorn A. Präferenzmessung im Gesundheitswesen: grundlagen von Discrete-Choice-Experimenten. Gesundheitsökonomie Qual. 2013; 18(04):159-72.

6 Epstein RM, Fiscella K, Lesser CS, Stange KC. Why the nation needs a policy push on patient-centered health care. Health Aff (Millwood). 2010 Aug;29(8):1489-95.

7 Ivandic V. Requirements for benefit assessment in Germany and England - overview and comparison. Health Econ Rev. 2014 Dec; $4(1): 12$.

8 daCosta DiBonaventura M, Copher R, Basurto E, Faria C, Lorenzo R. Patient preferences and treatment adherence among women diagnosed with metastatic breast cancer. Am Health Drug Benefits. 2014 Oct;7(7):386-96.

9 Omori Y, Enatsu S, Cai Z, Ishiguro H. Patients' preferences for postmenopausal hormone receptor-positive, human epidermal growth factor receptor 2-negative advanced breast cancer treatments in Japan. Breast Cancer. 2019 Sep;26(5):652-62.

10 Beusterien K, Grinspan J, Kuchuk I, Mazzarello S, Dent S, Gertler S, et al. Use of conjoint analysis to assess breast cancer patient preferences for chemotherapy side effects. Oncologist. $2014 \mathrm{Feb} ; 19(2): 127-34$.

11 Mühlbacher AC, Bethge S. Patients' preferences: a discrete-choice experiment for treatment of non-small-cell lung cancer. Eur J Health Econ. 2015 Jul;16(6):657-70.
12 Otto T, Stralka R, Schimmelpfennig H, Jung $\mathrm{H}$, Bruns K. Treatment options for patients with progressing type 2 diabetes: what are patients' preferences in GERMANY when switching from oral to injectable antidiabetic treatment? Gesundökon Qual Manag. 2016; 21:181-98.

13 Al-Omari B, Sim J, Croft P, Frisher M. Generating individual patient preferences for the treatment of osteoarthritis using adaptive choice-based conjoint (ACBC) analysis. Rheumatol Ther. 2017 Jun;4(1):167-82.

14 Cunningham CE, Deal K, Chen Y. Adaptive choice-based conjoint analysis: a new patientcentered approach to the assessment of health service preferences. Patient. 2010 Dec;3(4): 257-73.

15 Flood EM, Bell KF, de la Cruz MC, Ginchereau-Sowell FM. Patient preferences for diabetes treatment attributes and drug classes. Curr Med Res Opin. 2017 Feb;33(2):261-8.

16 Bridges JF, Hauber AB, Marshall D, Lloyd A, Prosser LA, Regier DA, et al. Conjoint analysis applications in health-a checklist: a report of the ISPOR Good Research Practices for Conjoint Analysis Task Force. Value Health. 2011 Jun;14(4):403-13.

17 Institute for Quality and Efficiency in Health Care (IQWiG). IQWiG Berichte Nr. 466: Präferenzmessung bei Parodontopathien GA15-01. Cologne: IQWiG; 2016.

18 International Committee of Medical Journal Editors (ICMJE). Recommendations for the conduct, reporting, editing and publication of scholarly work in medical journals: updated December 2018. ICMJE; 2018. pp. 1-19.

19 Corbin J, Strauss A. Basics of qualitative research: techniques and procedures for developing grounded theory. Thousand Oaks: Sage; 2014.
20 Mayring PH. Qualitative Inhaltsanalyse: Grundlagen und Techniken (11., aktualisierte und überarbeitete Auflage; 1. Auflage 1983). Weinheim: Beltz, 2010.

21 Sawtooth-Software - Technical Papers. The $\mathrm{CBC} / \mathrm{HB}$ system for hierarchical Bayes estimation: version 5.0. Available from: http:// www.sawtoothsoftware.com/download/techpap/hbtech.pdf

22 Sawtooth-Software - Technical Papers. Adaptive CBC papers. Available from: https:// www.sawtoothsoftware.com/support/technical-papers\#adaptive-cbc-papers.

23 Orme BK. Getting started with conjoint analysis: Strategies for product design and pricing research. Madison: Research Publishers; 2009.

24 de Bekker-Grob EW, Donkers B, Jonker MF, Stolk EA. Sample size requirements for discrete-choice experiments in healthcare: a practical guide. Patient. 2015 Oct;8(5):37384.

25 Johnson R, Orme B. Getting the most from CBC. Sequim: Sawtooth Software, 2003.

26 Beusterien K, Grinspan J, Tencer T, Brufsky A, Visovsky C. Patient preferences for chemotherapies used in breast cancer. Int J Womens Health. 2012;4:279-87.

27 Wouters H, Maatman GA, Van Dijk L, Bouvy ML, Vree R, Van Geffen EC, et al. Trade-off preferences regarding adjuvant endocrine therapy among women with estrogen receptor-positive breast cancer. Ann Oncol. 2013 Sep;24(9):2324-9.

28 Sledge GW Jr, Toi M, Neven P, Sohn J, Inoue $\mathrm{K}$, Pivot X, et al. MONARCH 2: abemaciclib in combination with fulvestrant in women with HR+/HER2- advanced breast cancer who had progressed while receiving endocrine therapy. J Clin Oncol. 2017 Sep;35(25) 2875-84. 